\title{
Influence of Initial Temperature and Convective Heat Loss on the Self-Propagating Reaction in A1/Ni Multilayer Foils
}

\author{
Mostafa Baloochi ${ }^{1, *}$, Deepshikha Shekhawat ${ }^{1}$, Sascha Sebastian Riegler ${ }^{2}$, Sebastian Matthes ${ }^{3}$, Marcus Glaser ${ }^{4}{ }^{\mathbb{D}}$,

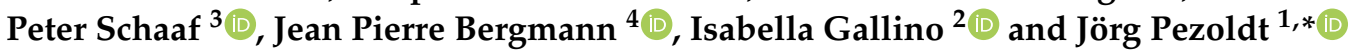 \\ 1 FG Nanotechnologie, Institut für Mikro-und Nanoelektronik, Institut für Mikro- und Nanotechnologien \\ MacroNano®, Institut für Werkstofftechnik, TU Ilmenau, Postfach 100565, 98684 Ilmenau, Germany; \\ deepshikha.shekhawat@tu-ilmenau.de \\ 2 Lehrstuhl für Metallische Werkstoffe, Universität des Saarlandes, Campus C6.3, 66123 Saarbrücken, Germany; \\ sascha.riegler@uni-saarland.de (S.S.R.); i.gallino@mx.uni-saarland.de (I.G.) \\ 3 FG Werkstoffe der Elektrotechnik, Institut für Werkstofftechnik, Institut für Mikro- und Nanotechnologien \\ MacroNano®, TU Ilmenau, Gustav-Kirchhoff-Strasse 5, 98693 Ilmenau, Germany; \\ sebastian.matthes@tu-ilmenau.de (S.M.); peter.schaaf@tu-ilmenau.de (P.S.) \\ 4 FG Fertigungstechnik, Institut für Mikro- und Nanotechnologien MacroNano®, TU Ilmenau, Postfach 100565, \\ 98684 Ilmenau, Germany; marcus.glaser@tu-ilmenau.de (M.G.); jeanpierre.bergmann@tu-ilmenau.de (J.P.B.) \\ * Correspondence: mostafa.baloochi@tu-ilmenau.de (M.B.); joerg.pezoldt@tu-ilmenau.de (J.P.)
}

check for

updates

Citation: Baloochi, M.; Shekhawat, D.; Riegler, S.S.; Matthes, S.; Glaser,

M.; Schaaf, P.; Bergmann, J.P.; Gallino,

I.; Pezoldt, J. Influence of Initial

Temperature and Convective Heat Loss on the Self-Propagating Reaction in $\mathrm{Al} / \mathrm{Ni}$ Multilayer Foils. Materials 2021, 14, 7815. https://doi.org/ $10.3390 /$ ma14247815

Academic Editor: Pavel Novák

Received: 19 November 2021 Accepted: 14 December 2021 Published: 17 December 2021

Publisher's Note: MDPI stays neutral with regard to jurisdictional claims in published maps and institutional affiliations.

Copyright: (c) 2021 by the authors. Licensee MDPI, Basel, Switzerland. This article is an open access article distributed under the terms and conditions of the Creative Commons Attribution (CC BY) license (https:// creativecommons.org/licenses/by/ $4.0 /)$.

\begin{abstract}
A two-dimensional numerical model for self-propagating reactions in $\mathrm{Al} / \mathrm{Ni}$ multilayer foils was developed. It was used to study thermal properties, convective heat loss, and the effect of initial temperature on the self-propagating reaction in $\mathrm{Al} / \mathrm{Ni}$ multilayer foils. For model adjustments by experimental results, these $\mathrm{Al} / \mathrm{Ni}$ multilayer foils were fabricated by the magnetron sputtering technique with a 1:1 atomic ratio. Heat of reaction of the fabricated foils was determined employing Differential Scanning Calorimetry (DSC). Self-propagating reaction was initiated by an electrical spark on the surface of the foils. The movement of the reaction front was recorded with a highspeed camera. Activation energy is fitted with these velocity data from the high-speed camera to adjust the numerical model. Calculated reaction front temperature of the self-propagating reaction was compared with the temperature obtained by time-resolved pyrometer measurements. X-ray diffraction results confirmed that all reactants reacted and formed a B2 NiAl phase. Finally, it is predicted that (1) increasing thermal conductivity of the final product increases the reaction front velocity; (2) effect of heat convection losses on reaction characteristics is insignificant, e.g., the foils can maintain their characteristics in water; and (3) with increasing initial temperature of the foils, the reaction front velocity and the reaction temperature increased.
\end{abstract}

Keywords: reactive materials; superlattice; nickel; aluminum; propagation velocity; self-sustained reaction; self-propagating reaction; transformation imprinted materials

\section{Introduction}

The Nickel and Aluminum binary system in different forms such as particles, powder, flakes, nanorods, and foils, were under intensive investigation since the end of the 20th century [1-13]. Fast and steady reaction and releasing a huge amount of energy on a very short time scale are the main beneficial aspects, applied in different fields of science and engineering. For example, applications are found in aerospace [14], thermal batteries [15], and potential application in drug delivery systems [16], where thermally actuated valving mechanism could be obtained by the development of reactive nanorods and porous thin films, and also at a smaller scale, such as joining electrical components in the semiconductor industry [17,18], welding [19], self-healing [20], etc. When the periodic bilayer thickness is less than $200 \mathrm{~nm}$, the diffusion length decreases, and atomic diffusion will play a dominating role in the direction normal to the multilayer surface and thermal diffusion along the layers will be the governing process. Consequently, the chemical mixing rate 
increases, and in presence of external stimulation, the reaction occurs in the in-plane direction of the binary film in high-temperature self-propagating mode. In this case, theoretically, the temperature could increase up to $1912 \mathrm{~K}$, which is the melting temperature of the NiAl B2 phase. The measured propagation velocity of the reaction front as reported in the literature is up to $15 \mathrm{~m} \mathrm{~s}^{-1}$, depending on the bilayer thickness and the intermixing at the interfaces between the layers [21,22].

Complexities and limitations of measurement devices and techniques drew attention towards analytical and numerical modeling of such reactions in multilayer foils [21,23-28]. In $[21,29]$, the reaction front velocity was investigated in dependence on bilayer and intermixing at the interface between the layers and it was concluded that the average combustion velocity increases, when the periodic thickness decreases, but below a critical thickness, where the intermixing zone becomes comparable to the bilayer thickness, this trend is inverted. Former models showed that this prior intermixing in the multilayers decreased the reaction front velocity by reducing the rate of atomic diffusion [23]. Different techniques have been implemented to measure the heat of reaction and the activation energy of the self-propagating reaction [30-33]. In the current study, the activation energy was fitted to the measured reaction front velocity from high-speed camera measurement. The reaction energy was measured by differential scanning calorimetry (DSC). In [34], the effect of activation energy and initial temperature on the reaction front velocity and the reaction temperature in the Ti-C system was studied. In the simulations performed here, this effect is considered for the $\mathrm{Al} / \mathrm{Ni}$ systems as well. In [27], a reduced model was introduced to investigate the reaction front velocity in direction normal to multilayers of uniform and non-uniform free-standing composite foils. In the current study, the effect of ambient conditions and the initial temperature of the foils on reaction characteristics were investigated. For this, a diffusion-limited finite element model was built with the help of COMSOL MULTIPHYSICS 5.6. To our knowledge, the influence of the initial temperature of nickel and aluminum multilayer foils on the characteristics of the reaction had not been investigated so far in the literature.

Due to different fabrication setups and environments, different microstructures are deposited, the main factors which are affecting the heat of reaction and consequently, the ignition properties of multilayer foils, are the bilayer thickness and premixing at the interface of the individual nickel and aluminum layers. The sputtering-induced alloying caused the formation of a few nanometer-thick NiAl intermetallic alloy at the interface of $\mathrm{Ni}$ and $\mathrm{Al}$, which can act as a diffusion barrier. For this reason, we have conducted the DSC analysis on sputtered samples. To adjust the numerical model, the results obtained from the simulations were compared with those of the experimental measurements from the highspeed camera detecting of the reaction front velocity and the temperature measurements by a high-speed pyrometer.

\section{Materials and Methods}

The summary of the conducted research is shown in Figure 1. In the first step, the alternating $\mathrm{Al}$ and $\mathrm{Ni}$ layers were deposited by magnetron sputtering to total multilayer thickness of $1 \mu \mathrm{m}$. After that, free-standing multilayers were fabricated using the mechanical exfoliation process. The formed free-standing foils were ignited using an electrical ignition spark between two measurement tips, placed on the surface of the reactive multilayer foils. The propagation velocity of the reaction front and the time-temperature behavior were recorded using a high-speed camera and a high-speed pyrometer, respectively. Free-standing thin films were additionally measured via DSC to obtain the total reaction enthalpy (heat release) during the reaction with slow heating rates. The obtained data were compared to the results of the simulations of the propagation velocity and the time-temperature dependence to adjust and validate the simulation model. 


\begin{tabular}{|c|c|c|}
\hline $\begin{array}{c}\text { Model } \\
\text { Development }\end{array}$ & $\begin{array}{l}\text { Adjustment and } \\
\text { Validation }\end{array}$ & Simulations \\
\hline $\begin{array}{l}\text { 1- Coupling of mass and } \\
\text { heat transfer equations } \\
\text { with concentration } \\
\text { dependent heat source as } \\
\text { a coupling parameter } \\
\text { (Section 2.1) } \\
\text { 2- Heat convective and } \\
\text { radiative boundary } \\
\text { conditions } \\
\text { (Section 2.1) } \\
\text { 3- Premixing layer with } \\
\text { different mathematical } \\
\text { functions } \\
\text { (Section 2.2) } \\
\text { 4- Temperature dependent } \\
\text { material properties from } \\
\text { literature data(Section 2.4) } \\
\text { 5- Ignition Initiation as a } \\
\text { boundary condition } \\
\text { (Section 2.5) }\end{array}$ & $\begin{array}{l}\text { 1- Heat of reaction of } \\
\mathrm{Al} / \mathrm{Ni} \text { foils is measured } \\
\text { by DSC (Section } 2.3,2.7 \text { ) } \\
\text { 2- Deposition of } \mathrm{Al} / \mathrm{Ni} \\
\text { multilayer foils } \\
\text { (Section } 2.6 \text { ) } \\
\text { 3- The activation energy } \\
\text { is fitted to velocity } \\
\text { measurements of the } \\
\text { high-speed camera } \\
\text { (Section } 2.7,3.1 \text { ) } \\
\text { 4- Ignition experiment } \\
\text { (Section } 2.5,2.7 \text { ) }\end{array}$ & $\begin{array}{l}\text { 1- Influence of premixing } \\
\text { thickness on characteristics } \\
\text { of the self-propagating } \\
\text { reaction (Section 3.2) } \\
\text { 2- Influence of NiAl } \\
\text { thermal conductivity on } \\
\text { characteristics of the self- } \\
\text { propagating reaction } \\
\text { (Section 3.3) } \\
\text { 3- Influence of convective } \\
\text { heat loss on characteristics } \\
\text { of the self-propagating } \\
\text { reaction (Section 3.4) } \\
\text { 4- Influence of initial } \\
\text { temperature of the foil on } \\
\text { characteristics of the self- } \\
\text { propagating reaction } \\
\text { (Section 3.5) }\end{array}$ \\
\hline
\end{tabular}

Figure 1. Summary of the current study.

\subsection{Model Description}

Schematic of deposited Ni and Al layers are illustrated in Figure 2a. The length $(L)$ of the model should be long enough to ensure that the finite size of the numerical domain is not affecting the characteristics of the self-propagating reaction [35]. On the other hand, it should be short enough to reduce computational costs. Therefore, the length of the multilayers is taken as $200 \mu \mathrm{m}$, to maintain a homogenous reaction front at different time steps. In Figure 2b, the formation of the reaction front and the intermixing zone of $\mathrm{NiAl}$, which will be discussed later, is represented.



(a)

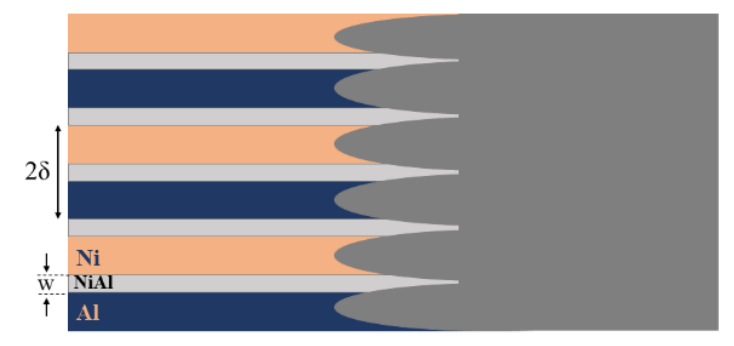

(b)

Figure 2. (a) Schematic of the implemented model. $Q_{\text {conv }}$ and $Q_{\text {rad }}$ are convective heat loss and radiative heat loss (b) enlarged view of the selected red area in (a), where $\mathrm{w}$ is the intermixing thickness of the multilayers and $2 \delta$ is the bilayer thickness.

A two-dimensional numerical model is implemented characterizing the self-propagating diffusion reaction of $\mathrm{Ni}$ and $\mathrm{Al}$ multilayers. The computational domain and also the thermal boundary conditions, such as convective and radiative heat losses are represented in 
Figure 2a. Mass transfer equation is coupled with heat transfer equation with a heat source term represented in the following:

$$
\frac{\partial C}{\partial t}=\nabla(D(T) \nabla C)
$$

Equation (1) is the mass transfer equation where $C$ is atomic species concentration of $\mathrm{Ni}$ and $\mathrm{Al}$, and $D$ is the diffusion coefficient which is described in Equation (2), where $D_{0}$ is the pre-exponential coefficient and $E_{a}$ is the activation energy, $R$ is the universal gas constant, and $T$ is the temperature. To perform the calculations, $D_{0}$, is taken from [29].

$$
D=D_{0} \exp \left(-\frac{E_{a}}{R T}\right)
$$

Equation (3) is the heat transfer equation, where $\rho$ is the temperature dependent density, $C_{p}$ is the temperature dependent specific heat capacity, $K$ is the temperature dependent thermal conductivity, and $Q(C)$ which is taken from [35] is the concentration dependent heat source, which couples the mass and heat transfer equation mentioned earlier and it is defined in Equation (4), where $H_{r x n}$ is the heat of reaction.

$$
\begin{gathered}
\rho(T) C_{p}(T) \frac{\partial T}{\partial t}=\nabla(K(T) \nabla T)+Q(C), \\
Q(C)=-\rho(T) H_{r x n} \frac{\partial C^{2}}{\partial t},
\end{gathered}
$$

The convective heat loss can theoretically be calculated from Equation (5) where $h$, is the convection coefficient, $T_{\infty}$, is the ambient temperature, and $A$ is the surface area from where the heat is transferred.

$$
Q_{\text {conv }}=h A\left(T_{\infty}-T\right),
$$

\subsection{Premixing and Concentration Profiles}

$\mathrm{Al}$ and $\mathrm{Ni}$ atoms are already intermixed during the sputtering process [20]. In Figure 3, the imposed concentration profile is plotted, as described; the primary concentration of $\mathrm{Al}$ and $\mathrm{Ni}$ and intermixed $\mathrm{NiAl}$ is considered $1,-1$, and 0 , respectively. The intermixed zone is implemented as linear and sinusoidal concentration profiles, as proposed in [35]. In an ideal case (no pre-intermixing), the concentration profile forms a step function as represented in Figure 3. The concentration distributions with a finite transition layer account for the existence of a premixing layer.

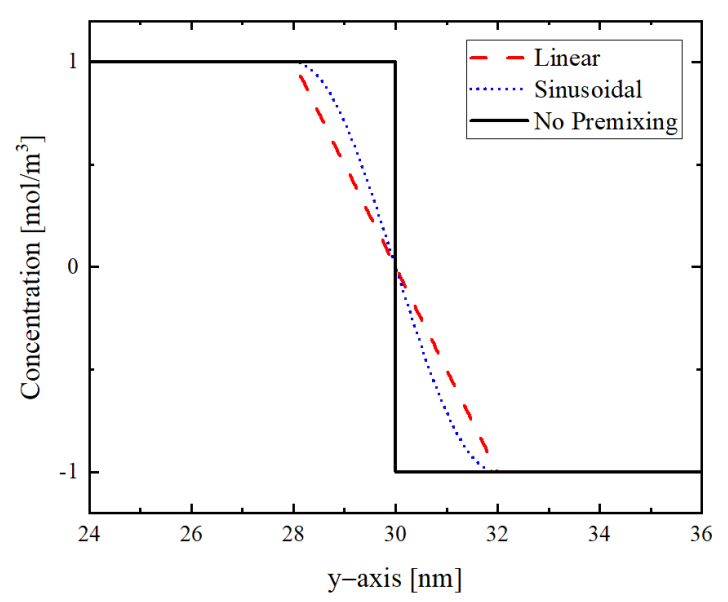

Figure 3. Possible mathematical concentration profile models of the intermixed zone at the bilayer interface and between the bilayers. 
In [36], the prediction of the premixing thickness of $4 \mathrm{~nm}$ is reported, which is also comparable with the DSC analysis done in this work. This will be elaborated in detail in the next subsections.

\subsection{Heat of Reaction}

Experimental and theoretical studies have been performed to measure and calculate the enthalpy of formation of the $\mathrm{B} 2 \mathrm{NiAl}$ phase $[30,37,38]$. As reported by [30], the enthalpy of formation of NiAl varies in the range of -57.2 to $-80 \mathrm{~kJ} \mathrm{~g}$-atom $^{-1}$. The negative sign is showing that the reaction is exothermic.

Due to the premixing of $\mathrm{Ni}$ and $\mathrm{Al}$ phases before the initiation of the self-propagating reaction, the heat, which is generated from the multilayer system decreases with the increasing thickness of the premixing layer $w$ as is illustrated in Figure $2 \mathrm{~b}$. This effect is well investigated in [9]. According to [9], the dependence of the heat of reaction, on the bilayer thickness and the premixing thickness can be described by Equation (6).

$$
H_{r x n}=H_{f}\left(1-\frac{w}{\delta}\right)
$$

where $H_{r x n}$ is the heat of reaction and $H_{f}$ is the enthalpy of formation of NiAl from its constituent phases.

The DSC measurement (see Section 2.7) conducted in this study is shown in Figure 4. The measured enthalpy of reaction of deposited $\mathrm{Al} / \mathrm{Ni}$ multilayers is $-55.01 \mathrm{~kJ}$ g-atom ${ }^{-1}$ (where $1 \mathrm{~g}$-atom $=1$ mole of atom) or $-1284 \mathrm{~J} \mathrm{~g}^{-1}$. This value, however, is measured by DSC for a constant slow heating rate of $20 \mathrm{~K} \mathrm{~min}^{-1}\left(0.333 \mathrm{~K} \mathrm{~s}^{-1}\right)$, and the reaction starts at around $400 \mathrm{~K}$ and is completed at $700 \mathrm{~K}$; it means that the reaction during the DSC annealing occurs exclusively in the solid-state. When the reaction is ignited at higher temperatures, where $\mathrm{Al}$ is in the molten state, the enthalpy of the reaction is expected to be more negative by at least $7 \mathrm{~kJ} \mathrm{~mol}^{-1}[30,39]$. With a prediction of a premixing thickness of $4 \mathrm{~nm}$ by [36] and Equation (6), we can estimate the enthalpy of formation of the NiAl phase being approximately $-65.5 \mathrm{~kJ} \mathrm{~g}$-atom $^{-1}$ or $-1528 \mathrm{~J} \mathrm{~g}^{-1}$, which is in good agreement with literature data reported in [30]. This value is taken to perform the numerical study.



Figure 4. Molar heat flow curve of free-standing thin films for an equiatomic $\mathrm{Al} / \mathrm{Ni}$ multilayer with a $50 \mathrm{~nm}$ bilayer periodicity measured with a constant heating rate of $0.333 \mathrm{~K} \mathrm{~s}^{-1}$. The red line displays the upper limit for the area of integration that was used for the determination of the total enthalpy release. 


\subsection{Material Properties}

The thermal properties, affecting the diffusion-driven reaction are thermal conductivity, density, and specific heat capacity of individual compounds and final product as well as intermetallic phases which are formed during the self-propagating reaction. The precision of implementation of these properties within the numerical model, makes simulation to be close to the real phenomenon of the $\mathrm{Ni}$ and $\mathrm{Al}$ reaction. For this, temperature dependent thermal properties are implemented. In [40], it was shown that NiAl crystalline phase is formed in $300 \mathrm{~ns}$, after passing of the reaction front. It is known that the diffusion rate after melting of $\mathrm{Al}$ at $933 \mathrm{~K}$ significantly increases due to liquid-solid diffusion instead of solid-solid diffusion. Therefore, the reactant mixing rate dramatically rises [41]. In the current study, it is assumed that the dominating phase formed at the propagation front is $\mathrm{NiAl}$; thus, we have adapted material properties and combined them as described in Figure 5. The isotropic material condition is assumed in this study, meaning that material properties are independent of direction.

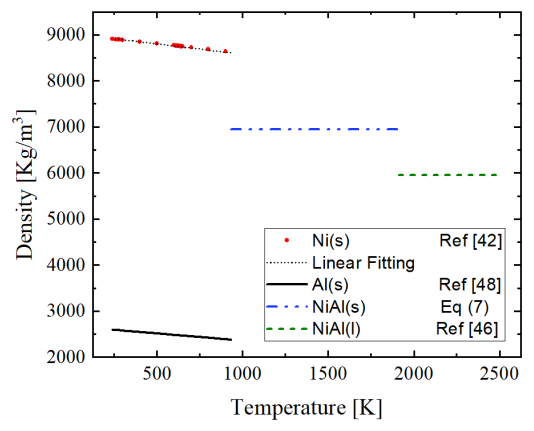

(a)



(b)

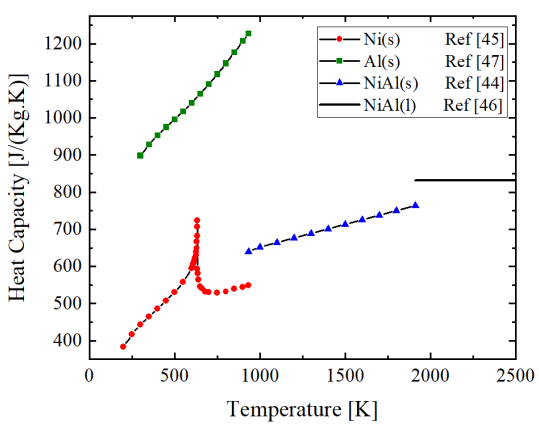

(c)

Figure 5. (a) Temperature dependent density of $\mathrm{Al}$ and Ni in solid-state; dotted line shows the linear fitting of data extracted from [42]. For temperatures greater than $933 \mathrm{~K}$, the density of $\mathrm{NiAl}$ in the solid and liquid state is plotted. (b) Temperature dependent thermal conductivity of Nickel and Aluminum in solid-state taken from [43]. It is combined with different values of thermal conductivity of product (NiAl). (c) Temperature dependent heat capacity of $\mathrm{Ni}, \mathrm{Al}$ in solid-state, and $\mathrm{NiAl}$ in both solid and liquid state extracted from [44-47].

The density of NiAl in the solid phase is estimated using Equation (7) as represented in Figure $5 \mathrm{a}$, where $M$ is the molar mass and $\rho$ is the density of the compound.

$$
\rho_{N i A l}=\frac{M_{N i} \rho_{N i}+M_{A l} \rho_{A l}}{M_{N i A l}}
$$

The Ni density data were extracted from [42] and linearly fitted. The fitting equation is described in Equation (8).

$$
\rho_{N i}=9028.1-0.44925 T T<T_{m, N i}
$$

where $T$ is the temperature in Kelvin, $\rho$ is the density in $\mathrm{kg} \mathrm{m}^{-3}$, and $T_{m, N i}$ is the melting point of Ni which is $1728 \mathrm{~K}$. The Aluminum density was extracted from [48] and described in Equation (9).

$$
\rho_{A l}=2378-0.3111(T-933) T<T_{m, A l},
$$

The melting point of $\mathrm{Al}$ is $T_{m, A l}=933 \mathrm{~K}$. Due to large deviations in thermal conductivity data at high temperature from the literature within the range of approximately $50-110 \mathrm{~W} \mathrm{~m}^{-1} \mathrm{~K}^{-1}$, we have studied the effect of different thermal conductivity values within this range on the velocity of reaction front and reaction temperature $[43,46,49]$. This is indicated in Figure 5b. 


\subsection{Ignition Initiator}

Ignition is obtained by imposing initial energy, which starts the self-propagating reactions in the deposited multilayers. The possibilities for ignition are laser pulses, mechanical impact, electrical spark, or uniform heating of the foils [50]. The last three methods of ignition were studied in [33], where the threshold of ignition energy in form of energy density was reported for different ignition techniques. Igniting with laser pulses is studied in [51] for the $\mathrm{Al} / \mathrm{Pt}$ system. In the current work, free-standing multilayer foils were ignited by the electrical current at $16 \mathrm{~V}$. In the numerical model, heat pulse of $10^{11} \mathrm{~W} \mathrm{~m}^{-2}$ for $1 \mu \mathrm{s}$ is applied on one side of the foil, to ensure the initiation of self-propagating ignition, while having insignificant thermal effects induced by the igniter.

\subsection{Al/Ni Multilayer Deposition}

The Ni and Al multilayers were prepared by magnetron sputtering using high purity $\mathrm{Al}$ and $\mathrm{Ni}$ targets in the PVD-Cluster $400 \mathrm{ES}$. Alternating layers of $\mathrm{Ni}$ and $\mathrm{Al}$, with layer thicknesses of $20 \mathrm{~nm}$ and $30 \mathrm{~nm}$ for $\mathrm{Ni}$ and $\mathrm{Al}$, respectively, were repeatedly deposited at room temperature onto $\mathrm{p}$-type $\mathrm{Si}(100)$ substrates, covered with a native silicon dioxide layer, until the overall film thickness of $1 \mu \mathrm{m}$ was reached. The starting layer was $\mathrm{Al}$. The $\mathrm{Ni}$ and $\mathrm{Al}$ thicknesses were chosen to achieve a nearly 1:1 atomic ratio of the two elements in the bilayer. In all of these layers, the bilayer thickness was $50 \mathrm{~nm}$.

\subsection{Ignition and Measurements}

The free-standing multilayer $\mathrm{Al} / \mathrm{Ni}$ foils were ignited electrically by placing two measurement tips on the surface of the foils at the edge of the samples. The distance between the tips was $1 \mathrm{~mm}$. The ignition was initiated by applying a voltage of $16 \mathrm{~V}$ between the tips. The velocity of the reaction front was recorded using a high-speed camera FASTCAM SA-X2 with a frame rate of 50,000 fps. The reaction temperature was measured using a high-speed KLEIBER-Pyrometer Pyroskop 840. The focus of the pyrometer was set to a predefined location and the temperature-time dependence was measured when the reaction front was passing it (see Figure 6).



(a)

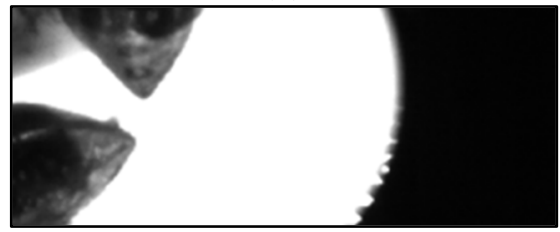

(c)

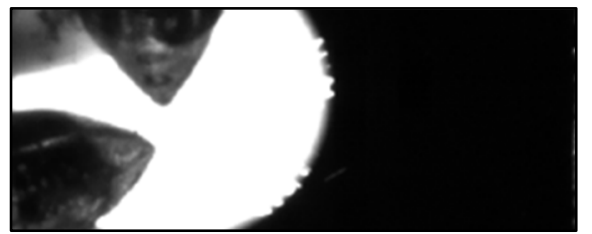

(b)

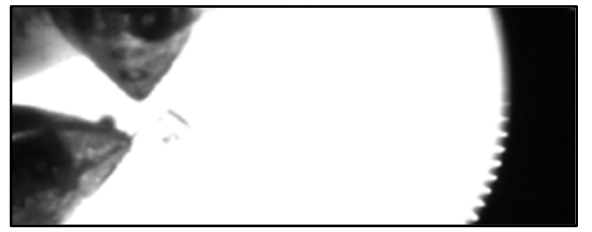

(d)

Figure 6. High-speed camera measurement. (a) At the time of ignition initiation, (b) $t=0.1 \mu \mathrm{s}$, (c) $\mathrm{t}=0.2 \mu \mathrm{s}$, and (d) $\mathrm{t}=0.3 \mu \mathrm{s}$.

In separate experiments, the heat of reaction of the $\mathrm{Al} / \mathrm{Ni}$ multilayer foils was determined by DSC measurements using a power-compensated Perkin Elmer Differential Scanning Calorimeter 8500 using $\mathrm{Al}$ crucibles under a constant flow of high-purity $\mathrm{Ar}$ (99.99 mol. \%) of $20 \mathrm{~mL} \mathrm{~min}^{-1}$ (see Section 2.3). The samples were heated with a constant rate of $0.333 \mathrm{~K} \mathrm{~s}^{-1}$ from 200 to $823 \mathrm{~K}$. A second run with the reacted material under identical conditions allowed for determining the baselines, which were subtracted from the first up-scan. The calorimeter was calibrated by measuring the melting temperatures and melting enthalpies of In and $\mathrm{Zn}$ [52]. Multiple pieces of the thin films have been stacked to reach a sufficient total mass for a good signal to noise ratio. 
The phase identification for the reacted and unreacted $\mathrm{Al} / \mathrm{Ni}$ free-standing foils was carried out by X-ray diffraction (XRD) (Bruker D5000 Theta-Theta X-ray diffractometer) with $\mathrm{Cu}-\mathrm{K} \alpha(1.5406 \dot{\mathrm{A}})$ radiation at $40 \mathrm{kV}$ and $40 \mathrm{~mA}$ in Bragg-Brentano working mode. Figure 7 depicts the $\mathrm{XRD}$ patterns of unreacted and reacted free-standing foils. It shows that before the reaction, the main peaks are belonging to $\mathrm{Al}$ (PDF 01-1179) and $\mathrm{Ni}$ (PDF 01-1179) and indicate the dominating presence of an fcc (111) orientation of $\mathrm{Al}$ and $\mathrm{Ni}$ elements in the unreacted free-standing foils. After the reaction, significant changes in the structure are shown by the elemental $\mathrm{Al}$ and Ni peaks disappearing and instead, exhibiting the $\mathrm{B} 2 \mathrm{Al}_{0.9} \mathrm{Ni}_{1.1}$ (PDF 44-1185) phase [53].

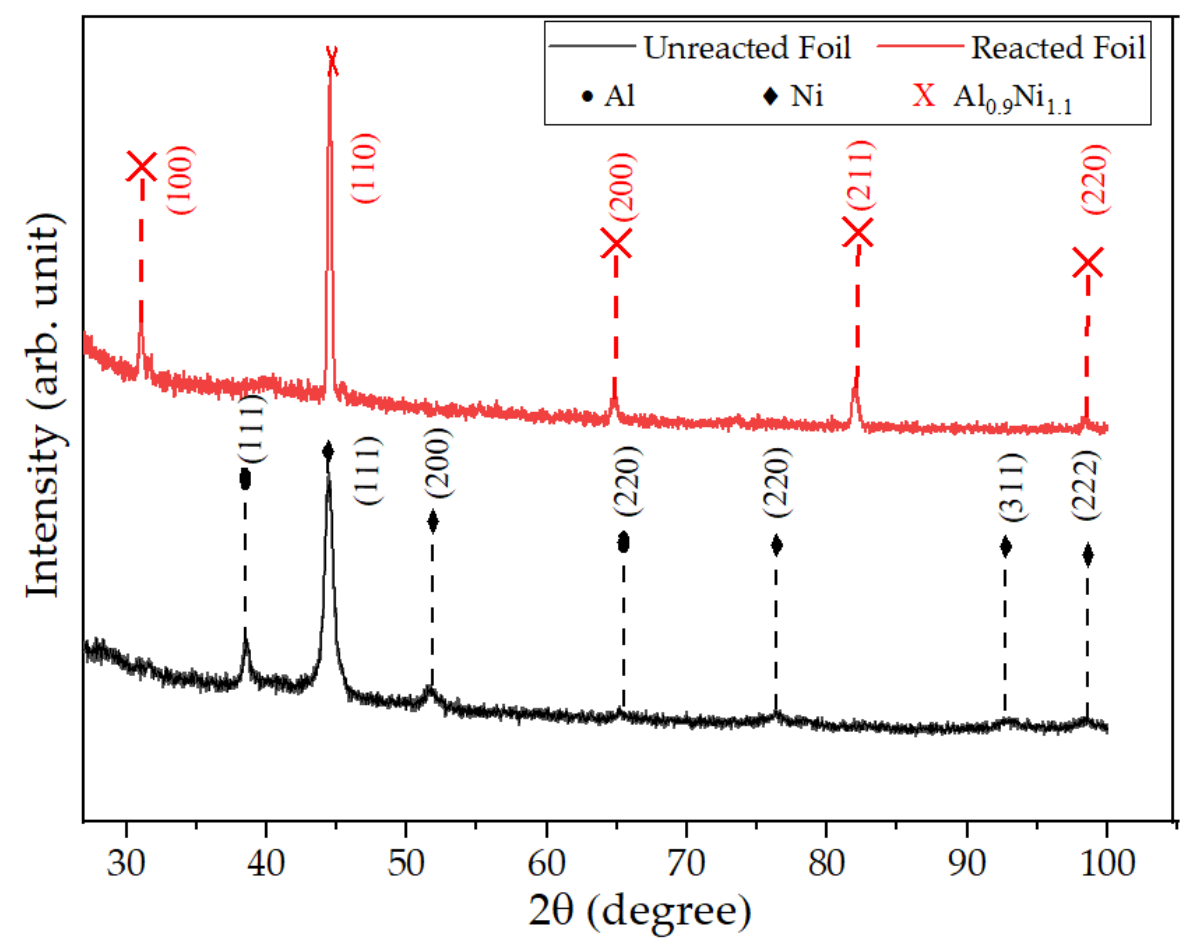

Figure 7. X-ray Diffraction analysis of free-standing $\mathrm{Al} / \mathrm{Ni}$ multilayer foils before and after the self-propagating reaction.

No additional phases were found which gives proof of the formation of the $\mathrm{Al}_{0.9} \mathrm{Ni}_{1.1}$ phase after the reaction. This $\mathrm{Ni}$ rich NiAl phase has already been observed due to changes in the composition of the grains in already existing phases [54].

\subsection{Foil Formation}

For the fabrication of the free-standing foils, a technique was used which is widely applied to exfoliate and transfer two dimensional materials to foreign substrates. It is the socalled dry transfer technique [55]. For the formation of the free-standing foils, the first step of this technique was used in a modified form. Specifically, a Kapton tape was mounted to the edge of the $\mathrm{Si}(100)$ substrate covered with the $\mathrm{Al} / \mathrm{Ni}$ multilayer. Subsequently, the $\mathrm{Al} / \mathrm{Ni}$ multilayer was exfoliated from the substrate. The Kapton foil was not removed from the foil edge, but used to mount the foil to the ignition set-up.

\section{Results and Discussion}

\subsection{Adjustment of Model Parameters}

The parametric validation of the developed model was conducted by relating the dependence of the simulated reaction propagation front velocity for a given width of the intermixing zone between the constituent layers of the bilayer stacks to the experimentally determined reaction front velocity. The correlation of the simulated and the experimentally 
determined reaction front velocity allows the determination of the $E_{a}$. In this approach, it was assumed that the width of the intermixing zone is equal for all interfaces.

Figure 8 illustrates the effect of the $E_{a}$ on the reaction front velocity and the reaction front temperature. The reaction front temperature is independent of the activation energy and is equal to $1499 \mathrm{~K}$. The measured temperature by high-speed pyrometer showed the maximum temperature of $1396 \mathrm{~K}$. The deviation of temperature results of simulation and measurement is about $7 \%$. This difference can be due to the finite integration time of the pyrometer used for the temperature measurements. Furthermore, it has to be mentioned that in the model, the interface roughness and waviness were not taken into account. The morphological real structure of the interface can influence the reaction temperature, as it acts as an effective medium and effectively increases the intermixing zone.

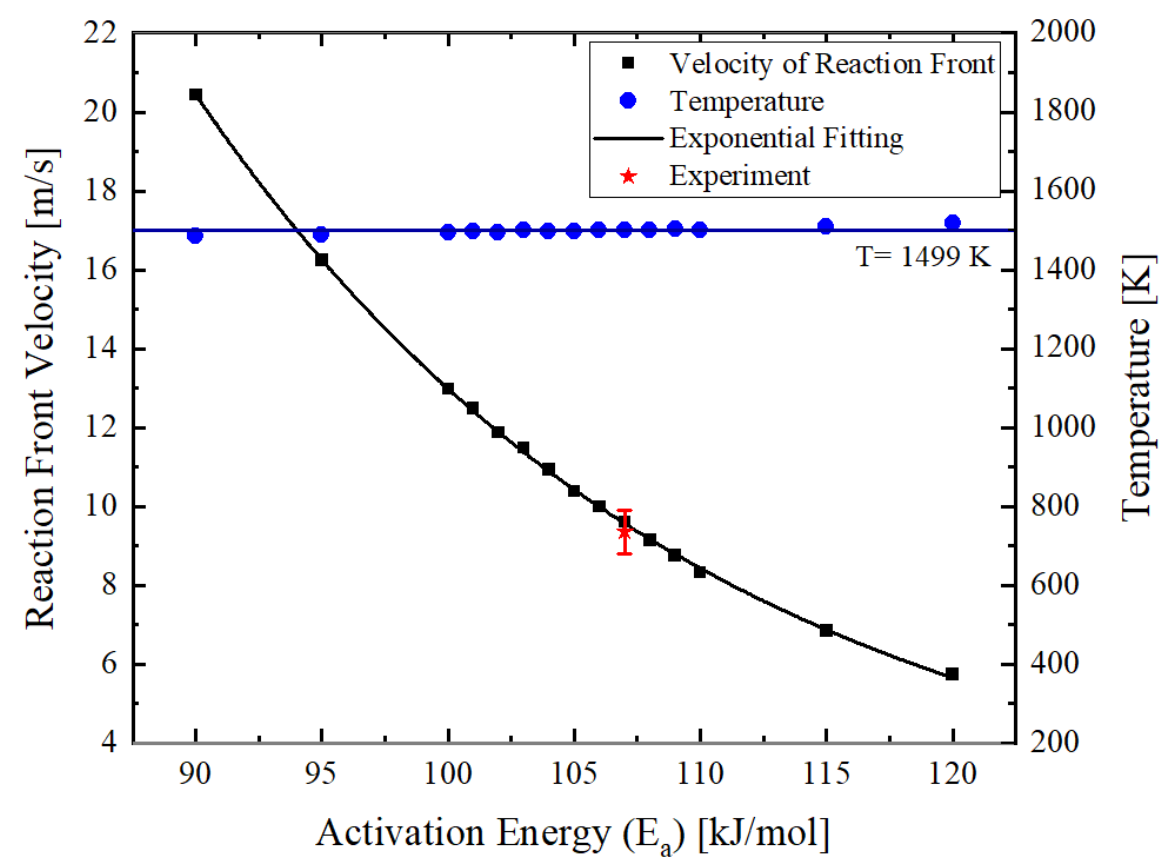

Figure 8. Effect of the activation energy of diffusion on the reaction front velocity and the reaction temperature at the reaction front. The width of the intermixing zone was set to $4 \mathrm{~nm}$.

The reaction front velocity decreases with increasing the activation energy $E_{a}$ following an exponential rule introduced in [56] and later implemented by $[9,36]$ as well. The application of the correlation procedure yields an $E_{a}=107 \mathrm{~kJ} \mathrm{~mol}^{-1}$. The obtained value agrees with the results obtained in $[57,58]$. For the following numerical investigations, this value was used for the activation energy.

\subsection{Influence of Premixing}

The influence of the thickness of the premixing zone at the interfaces between the two constituent materials is shown in Figure 9. Linear concentration profiles have a larger impact on both characteristics of the self-propagating reaction. Increasing premixing thickness causes a lower diffusion rate at the interface and a decrease in heat of reaction of $\mathrm{Ni}$ and $\mathrm{Al}$ which results in a lower propagation velocity of the reaction front. This is also mentioned in [35] and it is in good agreement with the effect of premixing (sinusoidal and linear) on the velocity of the reaction front and reaction temperature conducted in this study. 




(a)



(b)

Figure 9. The effect of sinusoidal and linear premixing zone (explained in Section 2.2) on (a) the reaction front velocity and (b) the reaction temperature at the reaction front, where $E_{a}=107 \mathrm{~kJ} \mathrm{~mol}^{-1}, D_{0}=2.18 \times 10^{-5} \mathrm{~m}^{2} \mathrm{~s}^{-1}$ and heat of reaction is calculated by Equation (6). (Lines are drawn to guide the eyes).

\subsection{Influence of NiAl Thermal Conductivity}

As mentioned in Section 2, the thermal conductivity of the reacting materials and the reaction product impacts the characteristics of the self-propagating reactions. On the other hand, the thermal properties of the initial materials in the bilayer stack and reaction product are affected by their real structures and therefore, depend on defect densities and composition. For the estimation of the impact of the thermal conductivity on the reaction front velocity, this parameter was varied. The results of the carried-out simulations are shown in Figure 10. According to the obtained results, the reaction front velocity increases nearly linear with the increase of the thermal conductivity of the final reaction product $\mathrm{NiAl}$.

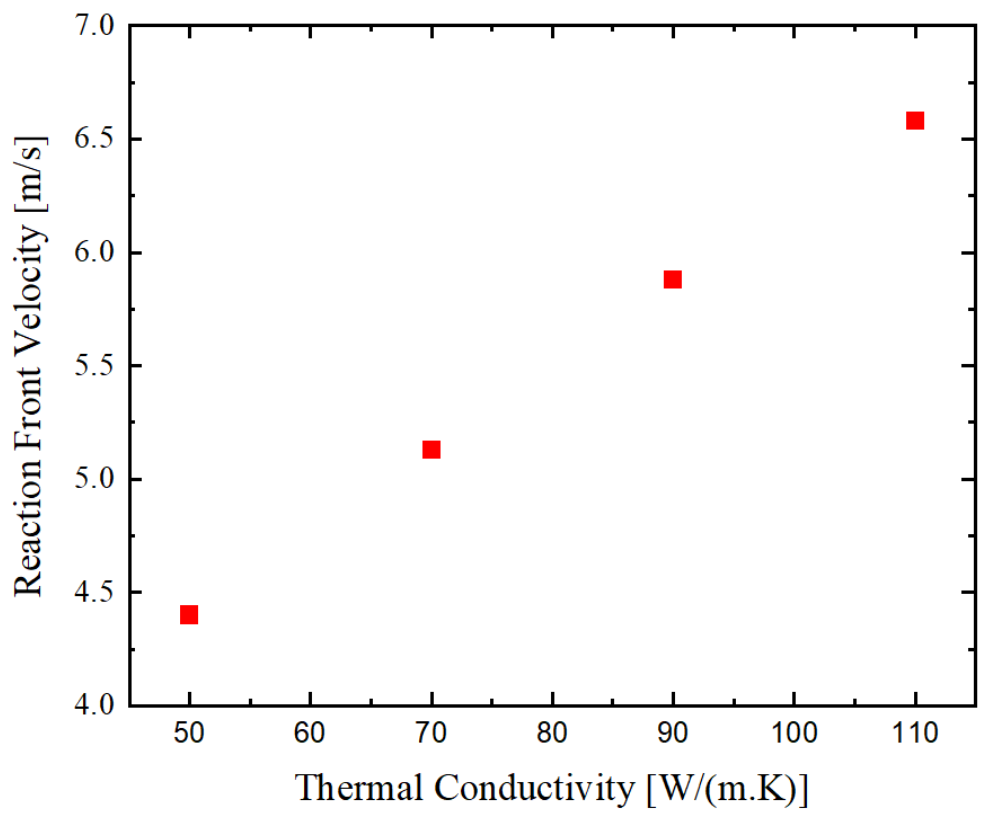

Figure 10. Influence of thermal conductivity of the final reaction product on the self-propagating reaction front velocity. 


\subsection{Influence of Convective Heat Loss}

Changing the ambient condition can cause change in the convective coefficient and consequently, affects heat loss from the multilayer foil to the environment (see Equation (5)). In Figure 11, the dependence of reaction front velocity and temperature at the reaction front on the convection coefficient is illustrated. Calculations showed in Figure 11 that for increasing convection coefficients from 5 to $15,000 \mathrm{~W} \mathrm{~m}^{-2} \mathrm{~K}^{-1}$, the propagation reaction front velocity decreases slightly. The relative decrease in the values of the reaction front velocity and the reaction temperature was obtained to be about 5 and $1.5 \%$, respectively.

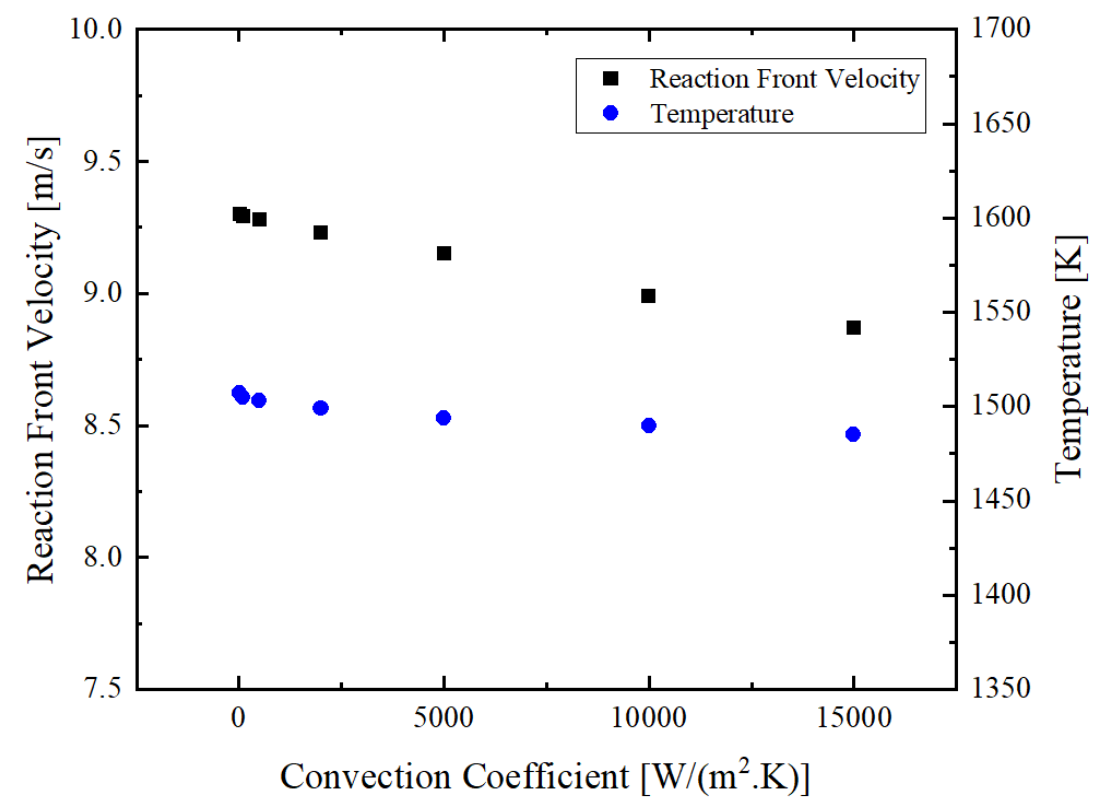

Figure 11. Effect of changing the ambient condition (convective coefficient) on the reaction front velocity and the temperature at the reaction front.

Therefore, increasing heat transfer coefficients causes a reduction in both characteristic values of the self-sustained reaction. Table 1 represents the convection coefficients related to these environmental conditions. From Table 1 and the calculations for different convection coefficients, we can conclude that multilayer foils behave similarly in an aqueous environment as they do in air.

Table 1. Convection Coefficient Examples (taken from [59]).

\begin{tabular}{cc}
\hline Convection Type & Convection Coefficient $\mathbf{h}\left(\mathbf{W} \mathbf{~ m}^{-\mathbf{2}} \mathbf{K}^{-\mathbf{1}}\right)$ \\
\hline Air, Free Convection & $2.5-25$ \\
Air, Forced Convection & $10-500$ \\
Liquid, Forced Convection & $100-15,000$ \\
\hline
\end{tabular}

\subsection{Influence of Initial Temperature}

In the previous subsections, the influence of the thermal conductivity and the heat loss conditions on the reaction front velocity and the reaction front temperature were studied. In Section 2.4, it was shown that the properties of the materials are affected by the temperature. Therefore, it is of interest to study the effect of the initial temperature of the multilayer foils. In [50], an ignition temperature of $521 \mathrm{~K}$ was measured on a hot plate for the solid-state reaction of $\mathrm{Al} / \mathrm{Ni}$ multilayer foils. The results of the calculations are summarized in Figure 12. It is predicted that, with increasing the initial temperature of the foils from room temperature up to the ignition initiation temperature, we are able to increase the reaction front velocity within the range of $5 \mathrm{~m} \mathrm{~s}^{-1}$ and the temperature at the reaction front within the range of $100 \mathrm{~K}$ (see Figure 12). 


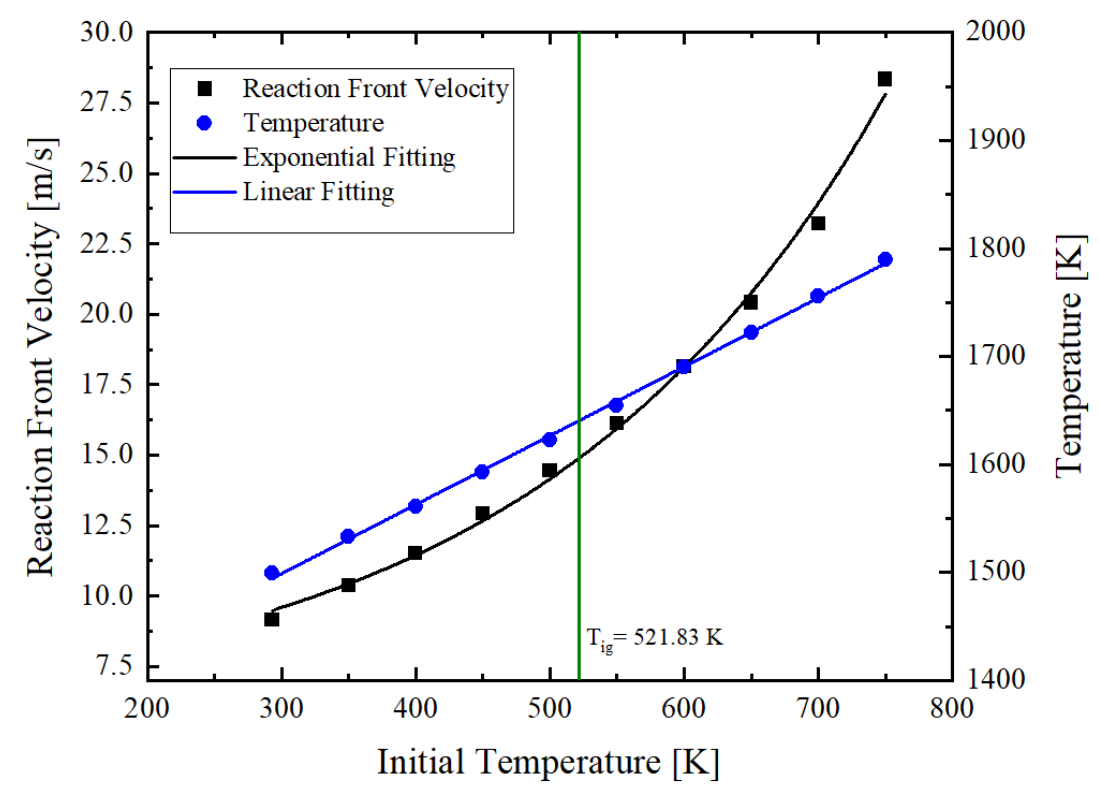

Figure 12. Influence of initial temperature of the reactive multilayer foil on the propagation reaction front velocity and temperature.

The increase of the reaction front velocity follows an exponential function whereas the reaction temperature obeys a linear law. Therefore, the initial temperature allows tuning both of these characteristic properties of the self-propagating reactions in reactive multilayer foils.

\section{Conclusions}

A two-dimensional numerical model was developed to investigate and analyze the influence of environmental variables and material properties on reaction front velocity and reaction temperature of reactive $\mathrm{Ni}$ and $\mathrm{Al}$ multilayer foils. For this, mass and heat transfer equations were coupled with a concentration dependent heat source as a coupling parameter. The interdiffusion of $\mathrm{Ni}$ and $\mathrm{Al}$ reactants and the formation of the final $\mathrm{NiAl}$ intermetallic alloy were considered. The boundary conditions of the interaction of the reactive multilayer system were determined by the heat dissipation conditions of a viscous medium, i.e., radiation, heat conduction, and convective losses have been chosen. Basic assumptions of the current study were as follows: (1) stoichiometric reaction of $\mathrm{Al}$ and $\mathrm{Ni}$, (2) only the NiAl phase exists at temperatures higher than melting temperature of aluminum, and (3) isotropic temperature dependent material properties. It is shown that with increasing thermal conductivity of the final product of the self-propagating reaction, the reaction front velocity increases. Convective cooling has an insignificant effect on reaction characteristics. It is predicted that $\mathrm{Ni}$ and $\mathrm{Al}$ multilayer foils can react in liquid as well as in an air environment. The characteristics of the reaction can be controlled, imposing the multilayer foils at different initial temperatures. With the increase of the initial temperature of the reactive multilayer systems, the velocity and the reaction temperature will increase.

Author Contributions: Conceptualization, M.B. and J.P.; methodology, M.B. and I.G.; software, M.B.; validation, M.B. and D.S.; investigation, M.B.; data curation, M.B., S.S.R., S.M., M.G. and I.G.; writing —original draft preparation, M.B. and J.P.; writing—review and editing, P.S., J.P.B. and J.P.; visualization, M.B., D.S. and J.P.; supervision, J.P. All authors have read and agreed to the published version of the manuscript.

Funding: This research was funded by the German Science Foundation under contracts PE 624/16-1, SCHA 632/29-1, SCHA 632/30-1, GA 1721/3-1 and BE 3198/7-1. We acknowledge support for the publication costs by the Open Access Publication Fund of the Technische Universität Ilmenau. 
Institutional Review Board Statement: Not Applicable.

Informed Consent Statement: Not Applicable.

Data Availability Statement: The data that support the findings of this study are available from the corresponding authors, M.B. and J.P., upon reasonable request.

Acknowledgments: The authors would like to express special thanks of gratitude to Yesenia Haydee Sauni Camposano, Konrad Jaekel and Joachim Döll, all of TU Ilmenau, for their help and support. Support by the Center of Micro and Nanotechnologies (ZMN), a DFG-funded core facility of TU Ilmenau, is also gratefully acknowledged. We acknowledge support for the publication costs by the Open Access Publication Fund of the Technische Universität Ilmenau.

Conflicts of Interest: The authors declare no conflict of interest.

\section{References}

1. Anselmi-Tamburini, U.; Munir, Z. The propagation of a solid-state combustion wave in Ni-Al foils. J. Appl. Phys. 1989, 66, 5039-5045. [CrossRef]

2. Gunduz, I.E.; Fadenberger, K.; Kokonou, M.; Rebholz, C.; Doumanidis, C.C. Investigations on the self propagating reactions of nickel and aluminum multilayered foils. Appl. Phys. Lett. 2008, 93, 134101. [CrossRef]

3. Hardt, A.; Phung, P. Propagation of gasless reactions in solids-I. Analytical study of exothermic intermetallic reaction rates. Combust. Flame 1973, 21, 77-89. [CrossRef]

4. Ito, S.; Inoue, S.; Namazu, T. The size limit of Al/Ni multilayer rectangular cuboids for generating self-propagating exothermic reaction on a Si wafer. In Proceedings of the 2013 Transducers \& Eurosensors XXVII: The 17th International Conference on Solid-State Sensors, Actuators and Microsystems (TRANSDUCERS \& EUROSENSORS XXVII), Barcelona, Spain, 16-20 June 2013; pp. 1927-1930.

5. Crone, J.C.; Knap, J.; Chung, P.W.; Rice, B.M. Role of microstructure in initiation of Ni-Al reactive multilayers. Appl. Phys. Lett. 2011, 98, 141910. [CrossRef]

6. Yang, C.; Hu, Y.; Shen, R.; Ye, Y.; Wang, S.; Hua, T. Fabrication and performance characterization of $\mathrm{Al} / \mathrm{Ni}$ multilayer energetic films. Appl. Phys. A 2014, 114, 459-464. [CrossRef]

7. Namazu, T.; Ito, S.; Kanetsuki, S.; Miyake, S. Size effect in self-propagating exothermic reaction of Al/Ni multilayer block on a Si wafer. Jpn. J. Appl. Phys. 2017, 56, 06GN11. [CrossRef]

8. Stover, A.; Krywopusk, N.; Fritz, G.; Barron, S.; Gibbins, J.; Weihs, T. An analysis of the microstructure and properties of cold-rolled Ni: Al laminate foils. J. Mater. Sci. 2013, 48, 5917-5929. [CrossRef]

9. Weihs, T. Fabrication and characterization of reactive multilayer films and foils. In Metallic Films for Electronic, Optical and Magnetic Applications; Elsevier: Amsterdam, The Netherlands, 2014; pp. 160-243.

10. Adams, D. Reactive multilayers fabricated by vapor deposition: A critical review. Thin Solid Films 2015, 576, 98-128. [CrossRef]

11. Mukasyan, A.S.; Rogachev, A.S.; Aruna, S.T. Combustion synthesis in nanostructured reactive systems. Adv. Powder Technol. 2015, 26, 954-976. [CrossRef]

12. Mukasyan, A.S.; Shuck, C.E.; Pauls, J.M.; Manukyan, K.V.; Moskovskikh, D.O.; Rogachev, A.S. The solid flame phenomenon: A novel perspective. Adv. Eng. Mater. 2018, 20, 1701065. [CrossRef]

13. Baras, F.; Turlo, V.; Politano, O.; Vadchenko, S.G.; Rogachev, A.S.; Mukasyan, A.S. SHS in Ni/Al nanofoils: A review of experiments and molecular dynamics simulations. Adv. Eng. Mater. 2018, 20, 1800091. [CrossRef]

14. Scheppe, F.; Sahm, P.; Hermann, W.; Paul, U.; Preuhs, J. Nickel aluminides: A step toward industrial application. Mater. Sci. Eng. A 2002, 329, 596-601. [CrossRef]

15. Zhu, Y.; Geng, J.; Wang, F.; Yan, S.; Zhao, P.; Meng, Q.; Wang, J.; Wu, Q. Preparation of Al/Ni reactive multilayer foils and its application in thermal battery. Z. Anorg. Allg. Chem. 2020, 646, 200-206. [CrossRef]

16. Kokonou, M.; Giannakopoulos, K.; Gunduz, I.; Fadenberger, K.; Rebholz, C.; Doumanidis, C. Reactive bimetallic Al/Ni nanostructures for nanoscale heating applications fabricated using a porous alumina template. Microelectron. Eng. 2009, 86, 836-839. [CrossRef]

17. Braeuer, J.; Besser, J.; Wiemer, M.; Gessner, T. A novel technique for MEMS packaging: Reactive bonding with integrated material systems. Sens. Actuator A 2012, 188, 212-219. [CrossRef]

18. Wang, J.; Besnoin, E.; Knio, O.; Weihs, T. Effects of physical properties of components on reactive nanolayer joining. J. Appl. Phys. 2005, 97, 114307. [CrossRef]

19. Swiston, A.J.; Besnoin, E.; Duckham, A.; Knio, O.M.; Weihs, T.P.; Hufnagel, T.C. Thermal and microstructural effects of welding metallic glasses by self-propagating reactions in multilayer foils. Acta Mater. 2005, 53, 3713-3719. [CrossRef]

20. Danzi, S.; Menetrey, M.; Wohlwend, J.; Spolenak, R. Thermal management in Ni/Al reactive multilayers: Understanding and preventing reaction quenching on thin film heat sinks. ACS Appl. Mater. Interfaces 2019, 11, 42479-42485. [CrossRef] [PubMed]

21. Gavens, A.; Van Heerden, D.; Mann, A.; Reiss, M.; Weihs, T. Effect of intermixing on self-propagating exothermic reactions in $\mathrm{Al} / \mathrm{Ni}$ nanolaminate foils. J. Appl. Phys. 2000, 87, 1255-1263. [CrossRef] 
22. Knepper, R.; Snyder, M.R.; Fritz, G.; Fisher, K.; Knio, O.M.; Weihs, T.P. Effect of varying bilayer spacing distribution on reaction heat and velocity in reactive Al/Ni multilayers. J. Appl. Phys. 2009, 105, 083504. [CrossRef]

23. Mann, A.; Gavens, A.; Reiss, M.; Van Heerden, D.; Bao, G.; Weihs, T. Modeling and characterizing the propagation velocity of exothermic reactions in multilayer foils. J. Appl. Phys. 1997, 82, 1178-1188. [CrossRef]

24. Jayaraman, S.; Mann, A.B.; Weihs, T.P.; Knio, O.M. A numerical study of unsteady self-propagating reactions in multilayer foils. In Proceedings of the Symposium (International) on Combustion, Boulder, CO, USA, 2-7 August 1998; pp. $2459-2467$.

25. Besnoin, E.; Cerutti, S.; Knio, O.M.; Weihs, T.P. Effect of reactant and product melting on self-propagating reactions in multilayer foils. J. Appl. Phys. 2002, 92, 5474-5481. [CrossRef]

26. Gunduz, I.E.; Fadenberger, K.; Kokonou, M.; Rebholz, C.; Doumanidis, C.C.; Ando, T. Modeling of the self-propagating reactions of nickel and aluminum multilayered foils. J. Appl. Phys. 2009, 105, 074903. [CrossRef]

27. Salloum, M.; Knio, O.M. Simulation of reactive nanolaminates using reduced models: II. Normal propagation. Combust. Flame 2010, 157, 436-445. [CrossRef]

28. Alawieh, L.; Weihs, T.P.; Knio, O.M. A generalized reduced model of uniform and self-propagating reactions in reactive nanolaminates. Combust. Flame 2013, 160, 1857-1869. [CrossRef]

29. Jayaraman, S.; Knio, O.; Mann, A.; Weihs, T. Numerical predictions of oscillatory combustion in reactive multilayers. J. Appl. Phys. 1999, 86, 800-809. [CrossRef]

30. Rzyman, K.; Moser, Z.; Watson, R.; Weinert, M. Enthalpies of formation of AlNi: Experiment versus theory. J. Phase. Equilib. 1998, 19, 106-111. [CrossRef]

31. Rzyman, K.; Moser, Z. Calorimetric studies of the enthalpies of formation of Al3Ni2, AlNi and AlNi3. Prog. Mater. Sci. 2004, 49, 581-606. [CrossRef]

32. Swaminathan, P.; Grapes, M.D.; Woll, K.; Barron, S.C.; LaVan, D.A.; Weihs, T.P. Studying exothermic reactions in the Ni-Al system at rapid heating rates using a nanocalorimeter. J. Appl. Phys. 2013, 113, 143509. [CrossRef]

33. Fritz, G.M.; Spey, S.J.; Grapes, M.D.; Weihs, T.P. Thresholds for igniting exothermic reactions in Al/Ni multilayers using pulses of electrical, mechanical, and thermal energy. J. Appl. Phys. 2013, 113, 014901. [CrossRef]

34. Lakshmikantha, M.; Bhattacharya, A.; Sekhar, J. Numerical modeling of solidification combustion synthesis. Metall. Mater. Trans. 1992, 23, 23-34. [CrossRef]

35. Kim, K. Numerical investigation of the self-propagation of intermetallic reaction waves in nanoscale aluminum/nickel reactive multilayer foils. Korean J. Met. Mater. 2019, 57, 97-107. [CrossRef]

36. Wang, T.; Zeng, Q.; Li, M. Characterization and application of $\mathrm{Al} / \mathrm{Ni}$ reactive multilayers in exploding foils. Cent. Eur. J. Energ. Mater. 2017, 14, 547-558. [CrossRef]

37. Ansara, I.; Sundman, B.; Willemin, P. Thermodynamic modeling of ordered phases in the Ni/Al system. Acta Metall. 1988, 36, 977-982. [CrossRef]

38. Burton, B.P.; Osburn, J.E.; Pasturel, A. Theoretical calculations of the NiAl-NiTi phase diagram based on first-principles linearmuffin-tin-orbital and full-potential linearly-augmented plane-wave cohesive-energy calculations. Phys. Rev. B Condens. Matter 1992, 45, 7677-7683. [CrossRef]

39. Wang, A.; Gallino, I.; Riegler, S.S.; Lin, Y.-T.; Isaac, N.A.; Camposano, Y.H.S.; Matthes, S.; Flock, D.; Jacobs, H.O.; Yen, H.-W.J.M.; et al. Ultrafast formation of single phase $\mathrm{B} 2 \mathrm{AlCoCrFeNi}$ high entropy alloy films by reactive $\mathrm{Ni} / \mathrm{Al}$ multilayers as heat source. Mater. Des. 2021, 206, 109790. [CrossRef]

40. Kim, J.; LaGrange, T.; Reed, B.; Knepper, R.; Weihs, T.; Browning, N.; Campbell, G. Direct characterization of phase transformations and morphologies in moving reaction zones in $\mathrm{Al} / \mathrm{Ni}$ nanolaminates using dynamic transmission electron microscopy. Acta Mater. 2011, 59, 3571-3580. [CrossRef]

41. Shteinberg, A.; Shcherbakov, V.; Munir, Z. Kinetics of combustion in the layered Ni-Al system. Combust. Sci. Technol. 2001, 169, 1-24. [CrossRef]

42. Abdullaev, R.; Kozlovskii, Y.M.; Khairulin, R.; Stankus, S. Density and thermal expansion of high purity nickel over the temperature range from $150 \mathrm{~K}$ to $2030 \mathrm{~K}$. Int. J. Thermophys. 2015, 36, 603-619. [CrossRef]

43. Alawieh, L.; Knio, O.M.; Weihs, T.P. Effect of thermal properties on self-propagating fronts in reactive nanolaminates. J. Appl. Phys. 2011, 110, 013509. [CrossRef]

44. Alexander, C.; Ogden, J.; Risser, S.; Wood, V.E. Thermodynamic characterization of NiAl. J. Chem. Thermodyn. 2009, 41, 610-616. [CrossRef]

45. Meschter, P.J.; Wright, J.W.; Brooks, C.R.; Kollie, T.G. Physical contributions to the heat capacity of nickel. J. Phys. Chem. Solids 1981, 42, 861-871. [CrossRef]

46. Li, H.; Sekhar, J. Numerical analysis for micropyretic synthesis of NiAl intermetallic compound. J. Mater. Sci. 1995, 30, 4628-4636. [CrossRef]

47. Desai, P. Thermodynamic properties of aluminum. Int. J. Thermophys. 1987, 8, 621-638. [CrossRef]

48. Valencia, J.J.; Quested, P.N. Handbook, ASM; ASM International: Russell Township, OH, USA, 2008; Volume 15, pp. 468-481.

49. Darolia, R.; Walston, W.; Nathal, M. NiAl alloys for turbine airfoils. Superalloys 1996, 1996, 561-570.

50. Fritz, G.M.; Grzyb, J.A.; Knio, O.M.; Grapes, M.D.; Weihs, T.P. Characterizing solid-state ignition of runaway chemical reactions in Ni-Al nanoscale multilayers under uniform heating. J. Appl. Phys. 2015, 118, 135101. [CrossRef] 
51. Yarrington, C.; Abere, M.; Adams, D.; Hobbs, M. Reactive nanolaminate pulsed-laser ignition mechanism: Modeling and experimental evidence of diffusion limited reactions. J. Appl. Phys. 2017, 121, 134301. [CrossRef]

52. Sauni Camposano, Y.H.; Riegler, S.S.; Jaekel, K.; Schmauch, J.; Pauly, C.; Schäfer, C.; Bartsch, H.; Mücklich, F.; Gallino, I.; Schaaf, P. Phase transformation and characterization of 3D reactive microstructures in nanoscale $\mathrm{Al} / \mathrm{Ni}$ multilayers. Appl. Sci. 2021, 11, 9304. [CrossRef]

53. Xiong, Y.-j.; Qiu, Z.-1.; Li, R.-d.; Yuan, T.-c.; Hong, W.; Liu, J.-h. Preparation of ultra-fine grain Ni-Al-WC coating with interlocking bonding on austenitic stainless steel by laser clad and friction stir processing. Trans. Nonferrous Met. Soc. China 2015, 25, 3685-3693. [CrossRef]

54. Kwiecien, I.; Bobrowski, P.; Wierzbicka-Miernik, A.; Litynska-Dobrzynska, L.; Wojewoda-Budka, J. Growth kinetics of the selected intermetallic phases in $\mathrm{Ni} / \mathrm{Al} / \mathrm{Ni}$ system with various nickel substrate microstructure. J. Nanomater. 2019, 9, 134. [CrossRef]

55. Castellanos-Gomez, A.; Buscema, M.; Molenaar, R.; Singh, V.; Janssen, L.; Van Der Zant, H.S.; Steele, G.A. Deterministic transfer of two-dimensional materials by all-dry viscoelastic stamping. 2D Mater. 2014, 1, 011002. [CrossRef]

56. Armstrong, R. Models for gasless combustion in layered materials and random media. Combust. Sci. Technol. 1990, 71, 155-174. [CrossRef]

57. Grapes, M.D.; Weihs, T.P. Exploring the reaction mechanism in self-propagating $\mathrm{Al} / \mathrm{Ni}$ multilayers by adding inert material. Combust. Flame 2016, 172, 105-115. [CrossRef]

58. Pauls, J.M.; Shuck, C.E.; Genç, A.; Rouvimov, S.; Mukasyan, A.S. In-situ transmission electron microscopy determination of solid-state diffusion in the aluminum-nickel system. J. Solid State Chem. 2019, 276, 114-121. [CrossRef]

59. Kosky, P.; Balmer, R.; Keat, W.; Wise, G. Mechanical Engineering. In Exploring Engineering; Elsevier: Amsterdam, The Netherlands, 2021; pp. 317-340. 